\title{
Tarsal switch using an anterior approach to correct severe ptosis
}

\author{
Roberta Lilian Fernandes de Sousa Meneghim ${ }^{1}$, Lucieni Barbarini Ferraz ${ }^{1}$, Alicia Galindo-Ferreiro ${ }^{2,3}$, \\ Rajiv Khandekar ${ }^{2}$, Hortensia Sanchez-Tocino ${ }^{3}$, Silvana Schellini ${ }^{1,2}$ \\ ${ }^{1}$ Department of Ophthalmology, Faculdade de Medicina de Botucatu-UNESP, São Paulo, Brazil; ${ }^{2}$ King Khaled Eye Specialist Hospital, \\ Riyadh, Saudi Arabia; ${ }^{3}$ Department of Ophthalmology, Rio Hortega University Hospital, Valladolid, Spain
}

Background To present the outcomes of the tarsal switch procedure using an anterior approach to correct severe ptosis with poor levator muscle function $(<4 \mathrm{~mm})$ with absent or poor Bell's phenomenon.

Methods This retrospective case series included 11 patients with severe neurogenic or acquired myogenic palpebral ptosis. All patients underwent the tarsal switch procedure through an anterior approach from 2012 to 2015. Margin reflex distance (MRD1 and MRD2) and the palpebral fissure were evaluated preoperatively and postoperatively. Data were compared using the Wilcoxon signed-rank test. P-values $<0.05$ were considered to indicate statistical significance.

Results Surgery was performed on 18 eyelids ( 11 patients). The median age at surgery was 57 years (range, 29-86 years). Four patients had unilateral ptosis and seven had bilateral ptosis. Nine patients had myogenic ptosis and two had neurogenic ptosis. Postoperatively, the chin-up position improved in all patients. The MRD1 increased statistically significantly, from $0 \mathrm{~mm}$ preoperatively to $1.0 \mathrm{~mm}$ postoperatively $(P=0.001)$. The MRD2 decreased statistically significantly, from $4.5 \mathrm{~mm}$ preoperatively to $3.0 \mathrm{~mm}$ postoperatively $(P=0.001)$. The palpebral fissure did not change ( $4.0 \mathrm{~mm}$ preoperatively to $4.0 \mathrm{~mm}$ postoperatively) $(P=0.13)$.

Conclusions The tarsal switch procedure through an anterior approach is an effective alternative for correcting severe ptosis, especially neurogenic or acquired myogenic ptosis. This procedure can be performed with minimal risk of ocular surface exposure and provides stable outcomes.

Keywords Blepharoptosis / Transplantation / Transplants
Correspondence:

Alicia Galindo-Ferreiro

Department of Ophthalmology, Rio

Hortega University Hospital, Dulzaina

Street 2, Valladolid 47012, Spain

Tel: $+34-983420400$

Fax: +34-983420400

E-mail: ali_galindo@yahoo.es

\section{INTRODUCTION}

Correcting ptosis can be challenging, especially in severe cases with poor levator muscle function and deficient extraocular motility, such as neurogenic (e.g., myasthenia gravis) or acquired myogenic ptosis (chronic progressive external ophthalmoplegia, oropharyngeal muscular dystrophy, or myotonic dystrophy) [14]. Many surgical approaches have been used to treat severe cases of these conditions, including blepharoplasty, conservative levator resection, multilevel full-thickness eyelid resection, and multiple partial frontalis suspension techniques [5].

The surgical technique must be meticulous, especially if fron- 
talis suspension or extensive resection of the levator muscle is performed, due to the risk of postoperative complications such as lagophthalmos and keratitis secondary to corneal exposure $[6,7]$.

The technique of harvesting a free tarsal graft from the upper lid with simultaneous transfer into the lower lid, known as the "tarsal switch," was first described in 1891 by Gillet de Grandmont $[8,9]$. Demartelaere et al. [10] suggested changes in the procedure and indications, reporting good outcomes for the correction of severe ptosis associated with myopathy. The tarsal switch has also been used for eyelid reconstruction, entropion repair [11], and to treat lower lid retraction.

The tarsal switch procedure is a palpebral fissure transposition, and it can be useful for correcting severe ptosis associated with deficient extraocular motility because it improves the eyelid position. Additionally, the tarsal switch does not result in corneal exposure because it switches the position of the eyelid opening, moving the lower and upper eyelids to a higher position with better pupillary clearance $[5,12]$. Currently, only 1 study has documented improvement of the lid position by using the posterior approach to harvest the graft from the upper lid [13].

This study evaluates the outcomes of tarsal switch surgery with a graft from the upper lid using an anterior approach, to highlight this technique as an alternative procedure for severe ptosis with poor levator function when Bell's phenomenon is absent [5].

\section{METHODS}

\section{Patients and measurements}

This retrospective study evaluated patients with severe acquired myogenic or neurogenic ptosis who were treated with the tarsal switch procedure. All patients underwent surgery from 2012 to 2015. This study adhered to the tenets of the Declaration of Helsinki and received approval of the Ethics Committee. Patients provided written informed consent for the operation. All patients had severe ptosis associated with poor levator muscle function, and Bell's phenomenon was absent or poor in all cases.

All patients underwent a comprehensive eye examination, including an assessment of visual acuity, slit lamp examination, tonometry, measurement of the margin reflex distance (MRD1 and MRD2) and palpebral fissure aperture, and an assessment of levator muscle function, extraocular muscle motility, and Bell's phenomenon.

The MRD1, MRD2, and the palpebral fissure were measured by 2 of the authors preoperatively and at least 12 months postoperatively. These measurements were performed with a ruler and a flashlight, with the observer at the same height as the pa- tient. The MRD1 was defined as the distance between the upper lid margin and the central pupillary light reflex. The MRD2 was defined as the distance between the lower lid margin and the central pupillary light reflex. The palpebral fissure was defined as the distance between the upper lid margin and the inferior lid margin, measured by a vertical line passing through the pupil center.

\section{Surgical procedure}

Surgery was performed under local anesthesia, and general anesthesia was used only for uncooperative patients. The skin crease was marked in the upper lid approximately $8 \mathrm{~mm}$ from the upper lid margin, and $2 \%$ lidocaine with epinephrine was then injected subcutaneously. A 4-0 silk traction suture was applied to the upper lid and a No. 15 blade was used to incise the skin and orbicularis muscle. The upper tarsal plate was exposed with Stevens scissors and released from the levator complex. Then, a tarsoconjunctival graft measuring approximately $4 \times 10$ $\mathrm{mm}$ was removed, preserving enough tarsus margin (at least 3 $\mathrm{mm}$ ) to avoid necrosis of the eyelid margin and instability. The aponeurosis of the levator muscle and conjunctiva were reinserted in the remaining upper tarsal plate with 3 simple singlearmed 6-0 polyester sutures (Polysuture, Johnson \& Johnson Ethicon LLC, San Lorenzo, USA) or 6-0 polyglactin sutures (Vicryl, Johnson \& Johnson-Ethicon LLC). Subsequently, the upper skin crease incision was closed with a running suture using a 6-0 non-absorbable monofilament suture (Nylon, Ethicon Inc., Somerville, NJ, USA) or a 6-0 rapid polyglactin suture (Vicryl, Johnson \& Johnson-Ethicon LLC). Then surgery was performed on the lower lid. The tarsoconjunctival graft was placed in the recipient bed located in the lower eyelid using a conjunctival approach. The conjunctiva was opened with a Westcott scissor immediately under the tarsal plate, the retractors were released, and the tarsal plate was exposed. Then, the tarsoconjunctival graft was sutured between the inferior tarsal plate and the inferior eyelid retractor with running 6-0 polyglactin (Vicryl, Johnson \& Johnson-Ethicon LLC) (Fig. 1). Patients with bilateral ptosis underwent bilateral surgery on the same day.

\section{Statistical analysis}

Data were collected preoperatively and at least 6 months postoperatively and were transferred to a Microsoft Excel spreadsheet (Microsoft Corp., Redmond, WA, USA). SPSS version 16.0 (SPSS Inc., Chicago, IL, USA) was used for univariate analysis with a non-parametric method. For qualitative variables, frequencies and percentages were calculated. Two-by-two tables were used to compare the outcomes. Two-sided P-values 


\section{Fig. 1. Drawing scheme of the tarsal switch technique}

(A) Drawing of the tarsal switch technique. (B) Upper lid crease incision and dissection of the tarsal plate with the lid crease marked. (C) The tarsal plate was excised with Westcott scissors and resected. (D) The levator aponeurosis and conjunctiva were sutured to the remaining tarsal plate. (E) The tarsoconjunctival graft was then transposed to the lower eyelid using a conjunctival approach and running sutures.

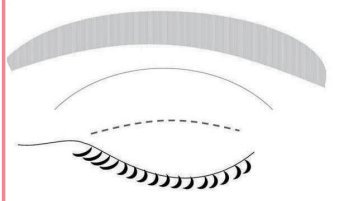

(A)

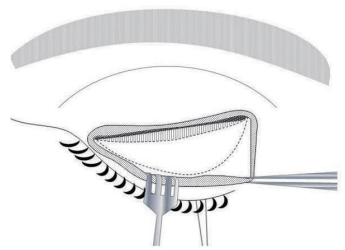

(B)

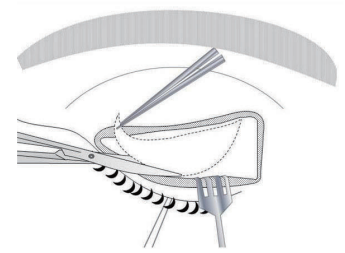

(C)

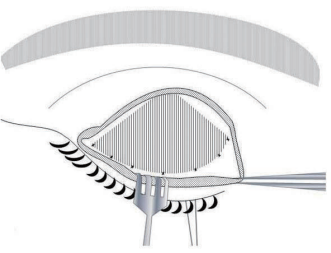

(D)

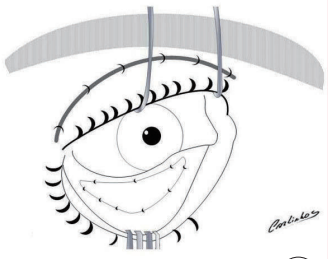

(E)

Table 1. Demographic information, ocular and systemic history of patients with neurogenic or myopathic ptosis who underwent the tarsal switch procedure

\begin{tabular}{|c|c|c|c|c|c|c|c|c|}
\hline Patient no. & Sex & $\begin{array}{l}\text { Age } \\
\text { (yr) }\end{array}$ & $\begin{array}{l}\text { Type of } \\
\text { ptosis }\end{array}$ & $\begin{array}{c}\text { Unilateral/ } \\
\text { bilateral } \\
\text { surgery }\end{array}$ & Diagnosis & $\begin{array}{l}\text { Family } \\
\text { history }\end{array}$ & $\begin{array}{l}\text { Other ocular } \\
\text { conditions }\end{array}$ & Systemic disease \\
\hline 1 & Female & 53 & Myopathic & Bilateral & Myasthenia gravis & No & Reduced eye motility & Thymectomy \\
\hline 2 & Female & 78 & Myopathic & Unilateral & Parkinson syndrome & No & Pseudophakia & None \\
\hline 3 & Male & 34 & Myopathic & Bilateral & $\begin{array}{l}\text { Mitochondrial } \\
\text { neuropathy }\end{array}$ & Yes & $\begin{array}{l}\text { Strabismus, reduced eye } \\
\text { motility }\end{array}$ & None \\
\hline 4 & Male & 61 & Myopathic & Bilateral & $\begin{array}{l}\text { Chronic progressive } \\
\text { external } \\
\text { ophthalmoplegia }\end{array}$ & Yes & $\begin{array}{l}\text { Strabismus, reduced eye } \\
\text { motility and diplopia }\end{array}$ & None \\
\hline 5 & Male & 70 & Myopathic & Bilateral & Not defined & Yes & Reduced eye motility & $\begin{array}{l}\text { Weakness, dysphagia, } \\
\text { and dysphonia }\end{array}$ \\
\hline 6 & Female & 50 & Myopathic & Bilateral & Not defined & No & Reduced eye motility & None \\
\hline 7 & Male & 64 & Neurogenic & Unilateral & III nerve palsy & No & Anophthalmic socket & None \\
\hline 8 & Female & 57 & Myopathic & Unilateral & Duane syndrome & No & $\begin{array}{l}\text { Esotropia, hypotropia of left } \\
\text { eye }\end{array}$ & Papillary thyroid cancer \\
\hline 9 & Male & 55 & Neurogenic & Bilateral & Myasthenia gravis & No & Frozen eyes & None \\
\hline 10 & Male & 29 & Myopathic & Bilateral & Steinert disease & No & Frozen eyes & None \\
\hline 11 & Male & 86 & Neurogenic & Unilateral & III nerve palsy & No & III Palsy & Diabetes \\
\hline
\end{tabular}

were calculated to assess statistical significance. The distribution of the outcome variables was evaluated. As the sample size was small with a wide variation in outcomes, the median, interquartile range (IQR), and minimum and maximum values were calculated. To assess statistical significance, median values were compared using the Wilcoxon two-sided P-value. P-values $<0.05$ were considered to indicate statistical significance.

\section{RESULTS}

\section{Patient demographics}

The study sample comprised 11 patients (18 eyelids). Seven patients underwent bilateral surgery. Their demographic and preoperative ocular characteristics are presented in Table 1.

The quantitative and qualitative parameters of the patients are summarized in Table 2.

The patients' median age was 57 years old (range, 29-86 years). Surgery was performed mainly in males (63\%), bilaterally (63\%), and in patients with myogenic ptosis (73\%), and only 3 cases $(27 \%)$ had other affected family members.

All the patients presented with a chin-up position preoperatively, and reduced ocular motility was observed in $91 \%$ of patients (Tables 1, 2).

The median MRD1 increased statistically significantly from $0.0 \mathrm{~mm}$ (IQR, $4.1 \mathrm{~mm}$ ) preoperatively to a median of $1.0 \mathrm{~mm}$ (IQR, $2.5 \mathrm{~mm}$ ) postoperatively. However, the median of the difference between both measures was $1.75 \mathrm{~mm}$ (mean, $2.3 \mathrm{~mm}$; range, 0-7 mm). The median MRD2 decreased statistically significantly from $4.5 \mathrm{~mm}$ (IQR, $0.5 \mathrm{~mm}$ ) preoperatively to 3.0 $\mathrm{mm}$ (IQR, $2.25 \mathrm{~mm}$ ) postoperatively. The median of the difference was $-1.5 \mathrm{~mm}$ (mean, $-1.8 \mathrm{~mm}$ ) (Table 3 ). The palpebral fissure did not change significantly, from $4.0 \mathrm{~mm}$ (IQR, 3.0 $\mathrm{mm}$ ) preoperatively to $4.0 \mathrm{~mm}$ (IQR, $2.75 \mathrm{~mm}$ ) postoperatively $(\mathrm{P}=0.13)$ Due to the wide range of postoperative results, there 
Table 2. Profile of patients with severe upper eyelid ptosis who underwent the tarsal switch procedure

\begin{tabular}{|ll|}
\hline Variable & Value \\
\hline Quantitative & \\
Age (yr) & \\
Median & 57 \\
$25 \%$ Quartile & 50 \\
Minimum & 29 \\
Maximum & 86 \\
Qualitative, no. (\%) & \\
Sex & \\
Male & $7(64)$ \\
Female & $4(36)$ \\
Laterality & \\
Unilateral & $4(36)$ \\
Bilateral & $7(64)$ \\
Family history of ptosis & \\
Yes & $3(27)$ \\
No & $8(73)$ \\
Cause of muscle weakness & \\
Myogenic & $9(82)$ \\
Neurogenic & $2(18)$ \\
Underlying pathologies & \\
III Nerve palsy & $2(18)$ \\
Myasthenia gravis & $2(18)$ \\
Parkinson syndrome & $1(9)$ \\
Duane syndrome & $1(9)$ \\
Progressive external ophthalmoplegia & $1(9)$ \\
Mitochondrial neuropathy & $1(9)$ \\
Steinert disease & $1(9)$ \\
Unknown & $2(18)$ \\
\hline & \\
\hline
\end{tabular}

were some important differences in the palpebral fissure in the cases with severe ptosis (mean, $0.8 \mathrm{~mm}$; range, -1.5 to $7 \mathrm{~mm}$ ).

\section{Outcomes and postoperative complications}

Postoperatively, all the patients had a good lid margin contour and an improved chin position. All patients were satisfied with the surgical outcomes.

The inferior eyelid of 1 patient (patient 3 ) was poorly positioned and was corrected by a tarsal strip procedure. Ptosis recurred in patient 4 at 10 months postoperatively. This patient underwent a new surgical procedure with resection of the levator aponeurosis. Patient 5 developed punctate keratitis postoperatively, which improved with topical lubricants (Fig. 2).

\section{DISCUSSION}

The outcomes of the current study confirmed that the tarsal switch procedure provides stable outcomes and is a good option for treating patients with severe ptosis with poor levator function and absent or poor Bell's phenomenon [13].

Severe ptosis can cause an abnormal head position and con-
Table 3. Margin reflex distance (MRD1 and MRD2) and palpebral fissure before and after the tarsal switch procedure

\begin{tabular}{|c|c|c|c|c|c|c|}
\hline & \multicolumn{2}{|c|}{ MRD1 (mm) } & \multicolumn{2}{|c|}{ MRD2 (mm) } & \multicolumn{2}{|c|}{$\begin{array}{c}\text { Palpebral } \\
\text { fissure }(\mathrm{mm})\end{array}$} \\
\hline & Before & After & Before & After & Before & After \\
\hline Eyes & 18 & 18 & 18 & 16 & 18 & 18 \\
\hline Median & 0.0 & 1.0 & 4.5 & 3.0 & 4.0 & 4.0 \\
\hline Interquartile range & 4.1 & 2.5 & 0.5 & 2.25 & 3.0 & 2.75 \\
\hline Minimum & -4.0 & -1.0 & 4.0 & 2.0 & 0.0 & 3.0 \\
\hline Maximum & 1.0 & 5.0 & 6.0 & 4.5 & 6.0 & 8.0 \\
\hline Significance & \multicolumn{2}{|c|}{$0.001^{\mathrm{a})}$} & \multicolumn{2}{|c|}{$0.001^{\mathrm{a}}$} & \multicolumn{2}{|c|}{$0.13^{\text {a) }}$} \\
\hline
\end{tabular}

comitant chin elevation. All the patients in the current study had a chin-up position preoperatively. Patients use this compensatory head posture to improve their visual field [5]. However, this position negatively impacts their quality of life, as it is difficult to perform daily activities while constantly maintaining the chinup position. Additionally, patients with a chin-up position may experience pain due to constant contraction of the neck muscles, and may be considered to be mentally handicapped by some $[5]$.

As observed in our study, patients with ptosis associated with myopathy have decreased or absent vergence [14]. Additionally, all patients in the current study had weak or absent Bell's phenomenon. These changes restrict the effectiveness of current surgical techniques and increase the risk of keratitis and lagophthalmos, warranting other alternate surgical interventions to improve eyelid closure [14].

Despite the low or absent eye motility, the upper transposition of the palpebral fissure in tarsal switch surgery simultaneously increased MRD1 and decreased MRD2, improving the palpebral opening and transposing the lower eyelid to a higher position, which improved the head position and protected the cornea. Hence, the tarsal switch procedure enables a change in the position of the palpebral fissure, allowing the patient to maintain a more normal chin position with better pupillary exposure. These outcomes allow the patient to perform daily activities with less discomfort, improve aesthetics and the patient's social life, and mitigate the risk of ocular damage $[5,13]$.

The tarsal switch technique (or variants thereof) has been successfully used to treat patients with anophthalmic sockets [12], myogenic ptosis [13], and neurogenic ptosis [5].

We harvested the tarsoconjunctival graft from the upper lid using an anterior approach, as recommended in the literature $[5,15]$. However, the graft can also be harvested through a posterior approach, with successful outcomes $[12,13]$.

To our knowledge, this is the first study of this technique to 


\section{Fig. 2. Preoperative and postoperative clinical pictures}

Preoperative image of patients with neurogenic ptosis (patients 3 and 6$)$; with frontal contraction, the pupillary axis was obstructed (A, C). At the 2-year follow-up, after the tarsal switch procedure, the position of the lids permitted better pupil exposure, and the chin-up position had improved $(B, D)$.
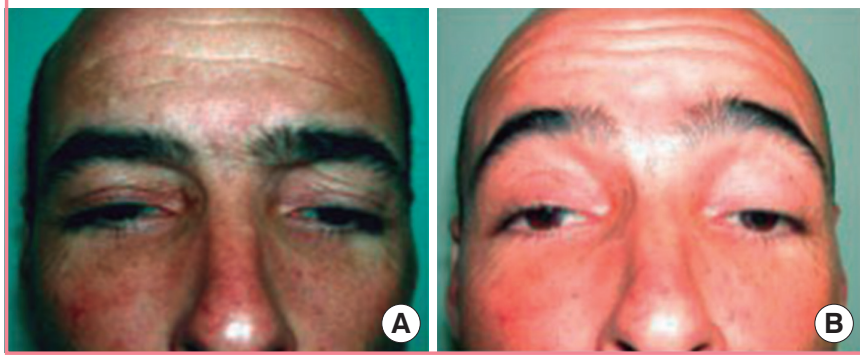

quantify the improvement experienced by patients and to report a statistically significant difference before and after surgery in MRD1, MRD2, and the palpebral fissure. The median MRD1 increased by $1.75 \mathrm{~mm}$, the median MRD2 decreased by $1.5 \mathrm{~mm}(\mathrm{P}<0.05$, all cases), and the palpebral fissure did not change postoperatively $(\mathrm{P}>0.05)$. A previous study of the tarsal switch with a posterior approach reported good outcomes, including a mean increase in MRD1 of $2.3 \mathrm{~mm}$ and a decrease in MRD2 by $1.6 \mathrm{~mm}$ [13]. Other studies did not quantify their measurements, only reporting cephalic displacement of the palpebral fissure [10,12].

The posterior approach resulted in residual nasal ptosis in more than half the patients, likely due to temporal decentration of the donor site. The same study also reported a thickened appearance of the pretarsal skin in $75 \%$ of cases postoperatively [12]. The tarsal switch procedure with an anterior approach results in good lid contour and better cosmesis because the residual or sectoral ptosis can be treated with simultaneous modification of the levator aponeurosis [5]. In the current study, no complications were found in which the incision of the orbicularis oculi worsened eyelid closure, as has been suggested by others [12]. This favorable outcome occurred because our technique did not involve orbicularis muscle excision.

The surgical step on the lower lid can be performed with a posterior approach, as we described in this study. However, an anterior approach is also possible, using a subciliary incision.

In our case series, only one patient developed punctate keratitis, which improved with topical lubricants, in agreement with other studies $[5,13]$. This was a minor complaint, as the patient was satisfied with the surgical procedure due to the ability to perform daily living tasks with greater ease.

The outcomes of the current study indicate that this procedure is stable. Ptosis recurred in only 1 lid at almost 1 year postoperatively in the current study. However, recurrence could be part of the natural process of the systemic disease, with the progression of myopathy and decreased muscle function.
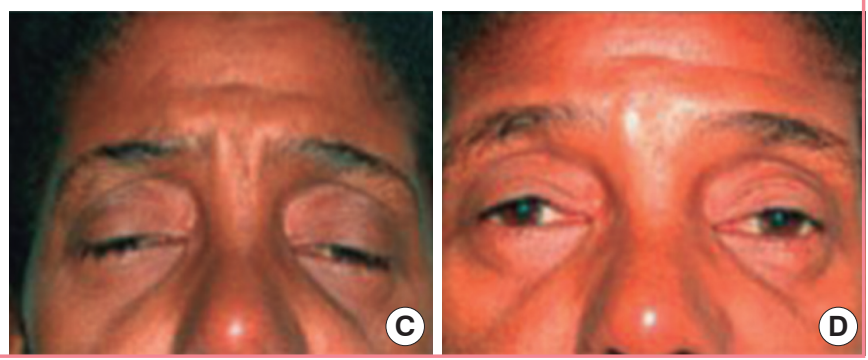

The limitations of our study include its retrospective nature and small sample size. However, other series investigating tarsal switch reported the outcomes of 26 [5] or 16 subjects [13]. The small sample sizes are because cases of myogenic and neurogenic ptosis are rare and because the relatively new procedure described in this study has slowly gained acceptance.

In conclusion, the tarsal switch procedure is an effective alternative treatment to correct severe ptosis with poor levator muscle function when Bell's phenomenon is absent. The procedure can be performed with minimal risk of conjunctival and corneal exposure and results in stable outcomes.

\section{NOTES}

\section{Conflict of interest}

No potential conflict of interest relevant to this article was reported.

\section{Ethical approval}

The study was approved by the King Khaled Eye Specialist Hospital (IRB No. 1597-CR) and performed in accordance with the principles of the Declaration of Helsinki. Written informed consents were obtained.

\section{Patient consent}

The patients provided written informed consent for the publication and the use of their images.

\section{ORCID}

Alicia Galindo-Ferreiro https://orcid.org/0000-0002-88549625

\section{REFERENCES}

1. Fox SA. Surgery for progressive familial myopathic ptosis. Ann Ophthalmol 1971;3:1033-8. 
2. Litwin AS, Patel B, McNab AA, et al. Blepharoptosis surgery in patients with myasthenia gravis. $\mathrm{Br} \mathrm{J}$ Ophthalmol 2015;99:899-902.

3. Weitgasser L, Wechselberger G, Ensat F, et al. Treatment of eyelid ptosis due to Kearns-Sayre syndrome using frontalis suspension. Arch Plast Surg 2015;42: 214-7.

4. Waller RR. Management of myogenic (myopathic) ptosis. Trans Sect Ophthalmol Am Acad Ophthalmol Otolaryngol 1975;79:697-702.

5. Demartelaere SL, Blaydon SM, Shore JW. Tarsal switch levator resection for the treatment of blepharoptosis in patients with poor eye protective mechanisms. Ophthalmology 2006;113:2357-63.

6. Osaki TH, Osaki MH, Belfort R Jr, et al. Management of progressive myopathic blepharoptosis with daily application of octyl-2-cyanoacrylate liquid bandage. Ophthal Plast Reconstr Surg 2009;25: 264-6.

7. Rizvi SA, Gupta Y, Yousuf S. Evaluation of safety and efficacy of silicone rod in tarsofrontalis sling surgery for severe congenital ptosis. Ophthal Plast Reconstr Surg 2014;30:114.

8. Reifler DM. The tarsectomy operation of A.P.L. Gillet de Grandmont (1837-1894) and its periodic rediscovery. Doc
Ophthalmol 1995;89:153-62.

9. Marple WB. A case of traumatic ptosis, operated according to method of Dr. Gruening or Gillet de Grandmont. Trans Am Ophthalmol Soc 1903;10(Pt 1):169-72.

10. DeMartelaere SL, Blaydon SM, Cruz AA, et al. Broad fascia fixation enhances frontalis suspension. Ophthal Plast Reconstr Surg 2007;23:279-84.

11. Stephenson CM, Brown BZ. The use of tarsus as a free autogenous graft in eyelid surgery. Ophthal Plast Reconstr Surg 1985;1:43-50.

12. Massry GG, Hornblass A, Rubin P, et al. Tarsal switch procedure for the surgical rehabilitation of the eyelid and socket deficiencies of the anophthalmic socket. Ophthal Plast Reconstr Surg 1999;15:333-40.

13. Lenake MN, McNab AA. The posterior approach tarsal switch procedure for myopathic ptosis: a modified technique. Ophthal Plast Reconstr Surg 2017;33:129-31.

14. Wong VA, Beckingsale PS, Oley CA, et al. Management of myogenic ptosis. Ophthalmology 2002;109:1023-31.

15. Lucci LM, Fonseca Junior NL, Sugano DM, et al. Tarsal switch levator for mitochondrial myogenic ptosis. Arq Bras Oftalmol 2009;72:159-63. 